\title{
DYSENTERY IN INFANCY
}

\author{
BY
}

I. A. SABRI, M.R.C.P., D.T.M. \& H., Assistant Physician; M. A. ABBOUD, M.R.C.P., Resident; and M. ALI, M.B., B.CH., D.T.M. \& H., Bacteriologist.

(From the Paediatric Department, Faculty of Medicine, Cairo.)

Dysentery is a common disease in Egypt. It affects children of all ages, but is most frequently encountered during the first two years of life. Thus, of 14,304 cases of dysentery examined at Fouad I Children's Hospital, during the last three years, 60 per cent. were in the first two years of life, 30 per cent. in the third to the sixth year and 10 per cent. in older children. The disease occurs sporadically during the whole year, but shows a marked increase during the hot summer months. Of the above mentioned 14,304 cases, 58 per cent. occurred in the four hot summer months of the year (May-August). Both breast- and artificially-fed infants suffer from the disease. The latter, however, are more commonly affected. Thus, of 3,000 infants below the age of one year who suffered from dysentery, the incidence of the disease was six times as great in artificially-fed infants as in the breast-fed. As in the case of other infections dysentery presents in infancy many of the features peculiar to this age period. With the aim of recording some of these features, the results of investigations carried out on a series of 100 cases of acute dysentery in infants and children under two years of age are presented.

\section{Diagnosis}

For the purpose of diagnosis a thorough stool and sigmoidoscopic examination was carried out in every case of the series. The latter method of examination was repeated regularly during the whole course of the disease in order to follow the progress of the cases closely.

(A) Stool examination.-The naked eye differences often described ${ }^{1,2}$ between amoebic and bacillary dysentery stools could not be clearly made out, and all attempts at such differentiation were unsuccessful. The cytological picture of the stools on the other hand, was of great help in the diagnosis. In many of the cases in which neither dysentery bacilli nor entamoebae were detected, the cellular picture of the stools was of value in suggesting the type of infection present. The advantages of making cultures as early as possible in the course of the disease are illustrated in the cases investigated. Seventy per cent. positive results were obtained from the cultures made in the first five days, fifty per cent. in the second 
five and only twenty-six per cent. in the third five days of the disease. The corresponding figures obtained by Martin and Williams ${ }^{3}$ were 68 per cent., $17 \cdot 4$ per cent. and 6.3 per cent. respectively.

In the following table are recorded the results of stool examination of the series of cases investigated:-

\begin{tabular}{|c|c|c|c|c|c|c|c|}
\hline B. dys. Flexner & group & $\ldots$ & $\ldots$ & $\ldots$ & $\ldots$ & $\ldots$ & 24 \\
\hline B. dys. Shiga & $\ldots$ & $\ldots$ & $\ldots$ & $\ldots$ & $\ldots$ & $\ldots$ & 4 \\
\hline B. dys. Sonne & $\ldots$ & $\ldots$ & $\ldots$ & $\ldots$ & $\ldots$ & $\cdots$ & $\mathbf{3}$ \\
\hline B. dys. Schmits & $\ldots$ & $\ldots$ & $\ldots$ & $\ldots$ & $\ldots$ & $\ldots$ & 1 \\
\hline B. Morgan No. & 1 & $\ldots$ & $\ldots$ & $\ldots$ & $\ldots$ & $\ldots$ & 10 \\
\hline B. paratyphoid & A & $\cdots$ & $\ldots$ & $\ldots$ & $\ldots$ & $\ldots$ & 1 \\
\hline B. faecalis alk. & $\ldots$ & $\ldots$ & $\ldots$ & $\ldots$ & $\ldots$ & $\ldots$ & 6 \\
\hline Strept. faecalis & $\ldots$ & $\ldots$ & $\ldots$ & $\ldots$ & $\ldots$ & $\ldots$ & 7 \\
\hline B. paracolon & $\ldots$ & $\ldots$ & ... & $\ldots$ & $\ldots$ & $\ldots$ & 4 \\
\hline Ent. histolytica & $\ldots$ & $\ldots$ & $\ldots$ & $\ldots$ & $\ldots$ & $\ldots$ & $\mathbf{5}$ \\
\hline Mixed infections & (Ent. & hist. + & B. dys.) & $\ldots$ & $\ldots$ & $\ldots$ & $\mathbf{5}$ \\
\hline Intestinal flagella & ates & $\ldots$ & $\ldots$ & $\ldots$ & $\ldots$ & $\ldots$ & 6 \\
\hline \multirow{2}{*}{ Not identified } & $\ldots$ & $\ldots$ & $\ldots$ & $\ldots$ & $\ldots$ & $\ldots$ & 24 \\
\hline & & & & & Total & $\ldots$ & 100 \\
\hline
\end{tabular}

It is evident, from the above table that both amoebic and bacillary dysentery are met with in infancy. The bacillary form, however, is by far the most common. In addition to the accepted causal organisms of dysentery, B. Morgan No. 1 and B. paratyphoid are considered by many workers ${ }^{4,5,6}$ as possible causes of the disease in early childhood. The rôle played by Strept. faecalis, B. faecalis alk. and B. paracolon in the aetiology of dysentery is not quite definite. These organisms are recognized by some investigators ${ }^{5,7}$ as causes of diarrhoea and dysentery. In the six cases in which intestinal flagellates alone were found on stool examination, the presence of lesions in the bowel characteristic of amoebic (two cases) and bacillary (four cases) dysentery could be demonstrated. Intestinal flagellates, however, are considered by many writers ${ }^{4,8,9,10}$ to be able to produce diarrhoeic and dysenteric symptoms in children.

(B) Sigmoidoscopic examination. - The experience obtained with the sigmoidoscope in the last few years in the diagnosis of affections of the large bowel has proved the great value of this instrument. On the whole, the sigmoidoscope affords a better and more rapid means of accurate diagnosis of the type of dysentery present than any other available means. Thus, whilst an accurate diagnosis of the type of dysentery could be arrived at by the sigmoidscope in 100 per cent. of the cases, a positive result was obtained by stool examination in only 74 per cent. Friedemann ${ }^{11}$ and Biggam and Arafa ${ }^{12}$ arrived at similar results in adults. The use of the sigmoidoscope in children is practically devoid of danger. The youngest infant of the series on which sigmoidoscopy was performed was two months old. Elaborate preparation of the patient, although a necessary step in the adult, is often not required in the child. The child is given in the early morning a simple water enema. Two or three hours later. 
sigmoidoscopic examination is carried out. The child is laid on his right side with the knees drawn up and the buttocks close to the edge of the table. This position is convenient to the patient and enables the nurse to have a good hold of the child. Sedative drugs were never needed.

Appearances. Before an attempt is made to describe the pathological appearances of the bowel in infants as seen through the sigmoidoscope, the normal picture must be known. For this purpose, thirty healthy infants below the age of two years, who had not suffered from any intestinal disturbance during the last three months, were investigated. The stools were examined and sigmoidoscopy was performed in the usual way. The mucous membrane of the bowel appears of a pink colour with a shiny, smooth surface and visible subepithelial venules. The colour of the bowel wall was compared with the various gradations of a haemoglobin scale (Tallqvist) and was found to correspond to 40-50 per cent. Hb. In bacillary dysentery the mucous membrane of the rectum and colon appears congested. The surface has lost its glossiness and bleeds easily on the slightest touch with the instrument. The subepithelial venules are no longer visible. In severe cases, whitish, necrotic patches are seen. They are superficial and after separation leave superficial erosions. The congestion is always more marked in the lower than in the upper parts of the colon. In mild cases, it extends only a short distance up the bowel and fades gradually into normal mucosa; but in severe cases, the congestion extends beyond the reach of the sigmoidoscope ( 8 inches). In cases of moderate severity, the colour of the inflamed mucosa corresponds to 70-80 per cent. $\mathrm{Hb}$., whilst in severe cases it may reach 100 per cent. In amoebic dysentery on the other hand, the sigmoidoscopic appearances are quite different. The mucous membrane retains its normal pink colour, the surface remains shiny and the subepithelial venules are visible. Scattered here and there over the healthy mucosa are seen yellowish spots and small rounded or oval ulcers $\left(\frac{1}{8}-\frac{1}{4}\right.$ inch) surrounded by congested areolae. The base of the ulcer is often covered with a yellowish-white exudate. The most common site for these ulcers is the lower part of the rectum and especially just inside the internal sphincter. On scraping these ulcers, living amoebae, often in large numbers, are obtained. Mixed forms of bacillary and amoebic dysentery are not uncommon. The sigmoidoscopic appearances are a combination of the above two types.

Five cases of mixed infection were met with; they were as follows :-

$$
\begin{aligned}
& \text { Ent. hist. + B. dys. Sonne } \quad \ldots \quad \ldots \quad \ldots \quad 1 \text { case. } \\
& \text {, , }, \text {, , , , Morgan } 1 \ldots 1 \text {, } \\
& \text {,, , } \quad+,, \quad, \quad \text { Flexner ... } \quad \ldots \quad \text {... } 3 \text { cases. }
\end{aligned}
$$

The information obtained from the sigmoidoscopic examination, may be summarized as follows:-

(1) An accurate diagnosis of the form of dysentery could be arrived at in all cases.

(2) The severity of the local conditions has no relation to the causal organism. The same organism may produce the most severe or the most 
mild inflammation. Organisms to which mild forms of dysentery are usually ascribed could produce the worst type of inflammation and vice versa.

(3) There is no intimate relationship between the severity of the local condition of the bowel and the general symptoms of the disease. In some cases with symptoms of marked general disturbance, the local condition of the bowel was by no means severe.

(4) Infection with more than one organism does not necessarily give rise to more severe affection of the bowel than others produced by one single organism.

(5) The return to normal of the bowel condition as seen by the sigmoidoscope was always later than that of the stools. The average interval was five days. In some cases, however, the interval was as long as nineteen days. O'Connor ${ }^{13}$ recorded observations on cases in which ulceration of the colon was still present after complete clinical cure. This is a point of some clinical importance. It shows that clinical cure of dystentery precedes the onset of actual cure of the bowel.

(6) Relapses always occurred before the onset of complete cure of the bowel as judged by the sigmoidoscope. Their occurrence was accompanied by aggravation of the local condition of the bowel.

\section{Clinical features}

Clinically, two main forms of the disease could be distinguished:-

(A) A simple form in which the local intestinal symptoms were the prominent feature. This constituted the majority of the cases (85 per cent.). Apart from the characteristic stool picture, abdominal pain and occasional vomiting, the general condition of the child was not much affected. To this form belong cases of amoebic infection, and the majority of bacillary cases of mild or moderate severity.

(B) A toxic form in which symptoms of intoxication predominated. It accounts for 15 per cent. of the cases. In these the general symptoms of dehydration, disturbed consciousness and toxic respiration were prominent. They were all bacillary cases, and the causal organisms were:-
B. dys. Shiga
3 cases (out of 4 in the whole series)
(1 died)
B. dys. Flexner 4 cases
B. dys. Sonne 1 case
B. Morgan
2 cases
(1 died)
Not identified 5 cases

It is evident from the above that the majority (75 per cent.) of Shiga infections are of the severe form of dysentery. The other habitually less toxic organisms, however, could also produce severe forms of dysentery and, in fact, they account for the majority of toxic cases ( 80 per cent.) in the present series.

This may also explain the failures frequently obtained by the treatment of dysentery in infancy by the administration of antidysenteric serum. Serum, as is well known, is most potent against infections with the Shiga bacillus. Its effects in dysenteries due to other organisms are much less striking. Since the majority ( 80 per cent.) of the severely toxic cases of 
infantile dysentery are produced by organisms other than B. dys. Shiga, little is to be expected from the use of serum in most cases.

Complications.- The complications met with in the above cases were as follows:-Bronchopneumonia, 2 cases; oedema, 3 cases; pyuria, 19 cases (pus cells exceeding 50 per c.mm. of uncentrifugalized urine); and prolapse of rectum, 15 cases.

Duration.-The duration of the diseases in bacillary cases was not intimately related to the causal organism. Cases due to Flexner infection, for example, lasted a variable time between eight and twenty-two days. Those due to other organisms also showed similar variations. The duration of the disease in the cases of bacillary dysentery that were completely cured ( sigmoidoscopically) before discharge was as follows :-7-10 days in 7 cases; 11-20 days in 50 cases; and 21-28 days in 19 cases.

Relapses.-Recurrence of symptoms with the reappearance of dysenteric stools occurred in nine cases. They all occurred after apparent clinical cure before the onset of actual cure of the bowel. The symptoms lasted for a few days and were accompanied by some aggravation of the bowel condition. No dietetic faults were responsible for these relapses. This agrees with the experience of Albert and Quiason ${ }^{14}$ and Meyer and Nassau ${ }^{15}$.

\section{Dietetic therapy}

With the exception of amoebic cases, which received in addition specific drugs, the treatment adopted was purely dietetic. Drugs of known action on the bowel such as cathartics and astringents, were not used. Antidysenteric serum was not administered in any case. The repeated failure of serum therapy in infantile dysentery experienced in the Fouad I Children's Hospital, Cairo, and reported by many other workers ${ }^{12,13,14}$ encouraged this step. The diet used in each case was studied from the point of view of its effect on the general condition of the child, as well as on the local condition of the bowel.

The lines of treatment may be summarized thus:-

(a) A preliminary stage of complete starvation of six to twelve hours, during which boiled water or weak infusions of tea or caraway sweetened with saccharin is given.

(b) An intermediate stage of milk-free diet during which concentrated rice gruel 10 per cent. (after Bessau ${ }^{16,17}$ ), sweetened with 5 per cent. dextrimaltose, is given at three or four hourly intervals. Abundant amounts of fluids are offered between the feeds. The duration of this stage varies between one and three days according to the severity of the symptoms and the state of nutrition of the child.

(c) The third stage, during which milk or some other food is gradually introduced after the step-ladder scheme of Finkelstein.

(d) A final stage of return to normal diet is not attempted until complete cure, as judged by the sigmoidoscope, is established. 
Amoebic cases, in addition to dietetic treatment, received injections of emetine hydrochloride ( $\frac{1}{6}$ grain daily for six days) combined with enemata of a 2 per cent. solution of yatrin 105.

The diets used in feeding the above cases were:-

1. Human milk. Breast-fed infants were continued on the breast. After a short period of starvation, the child was given the breast for gradually increasing periods. Toxic cases were given expressed human milk in smaller quantities.

2. Buttermilk. This was given to artificially-fed infants below the age of six months. Powdered buttermilk (Beurlac, Cow \& Gate) was used in one in ten dilution. Rice gruel 2 per cent. was used as the diluent and 5 per cent. dextrimaltose was added.

3. Protein milk. This was given to artificially-fed infants above the age of six months. Powdered protein milk (Prolac, Cow \& Gate) was prepared in the same way as buttermilk and in a dilution of one in twelve.

4. Apple Diet (modified from Heisler and Moro). This was given to children above one year of age. In the first two days scraped raw apple or Aploma powder 8 per cent. suspension, was given in five meals. In the subsequent days, sweet white cheese, dry toasted bread (Zwieback), mashed bananas, boiled lean minced meat, mashed potatoes, boiled rice, vegetable purée were gradually introduced.

5. Carbohydrate Diet. This was given to another group of children similar to those given apple diet. After a day or two on rice gruel, 10 per cent. sweetened with 5 per cent. saccharose, a diet rich in carbohydrates was given consisting of arrow-root made rather thick, boiled rice, toasted bread and mashed potatoes. Purée vegetables and milk were given later.

In the following table are shown the results of the treated cases:-

\begin{tabular}{|c|c|c|c|c|c|c|c|}
\hline & DIET. & Cases. & Gair & $\begin{array}{l}\text { EIGH } \\
\text { nsta }\end{array}$ & Loss. & $\begin{array}{l}\text { SToors. } \\
\text { Return to normal. }\end{array}$ & $\begin{array}{l}\text { Sigmoidoscope. } \\
\text { Return to normal. }\end{array}$ \\
\hline 1. & Human milk & 20 & 1 & 12 & 7 & after 8 days & after 11.6 days \\
\hline 2. & Protein milk & 20 & 10 & 5 & 5 & after 6.3 days & after 13 days \\
\hline 3. & Butter milk & 16 & 6 & 6 & 4 & after 6.6 days & after 12.3 days \\
\hline 4. & Apple diet & 10 & 7 & 3 & 0 & after 6 days & after 11.9 days \\
\hline 5. & Carb. diet & 10 & 1 & 4 & 5 & after 8.9 days & after 12.8 days \\
\hline
\end{tabular}

\section{Discussion}

In reviewing these results the following points are noted:-

(1) Under dietetic measures alone and without the help of any drug or serum, cases of bacillary dysentery were cured. Cases of toxic dysentery were also treated on the same lines, and apart from special measures aimed at combating collapse and dehydration, no other medication was administered. The majority of the toxic cases ( 73 per cent.) recovered.

(2) The majority of children given human milk did remarkably well. The mortality rate ( 5 per cent.) was definitely lower than in artificially-fed 
infants (10 per cent.). The return of the stools to normal, however, did not take place rapidly and the gain in weight was slight or altogether lacking. Human milk, being rich in fat and lactose, is a poor antidyspeptic diet. Its poverty in protein and salts explains the defective gain in weight.

(3) With protein and buttermilks, the return of stools to normal was rapid and the gain in weight marked. These two milks are acidified and have a low fat and high protein and salt content. They are good antidyspeptic and antidystrophic diets.

(4) Apple diet gave satisfactory results. The therapeutic effects of apples and bananas are ascribed ${ }^{18,19}$ to pectin which probably acts by its buffer qualities, its adsorptive capacities and its ability to bind amines. The other constituents of apples and bananas, mainly malic acid, tannin and cellulose probably play a minor rôle. The high protein diet that follows accounts for the marked gain in weight and rapid return of stools to normal consistency.

(5) High carbohydrate diet was disappointing in its results. In the majority of cases diarrhoea persisted for a long time and gain in weight was lacking. One patient showed a false gain in weight by developing oedema. This oedema is mainly due to protein hunger (mehlhnährschaden) ${ }^{20}$ and is accompanied by low plasma protein ${ }^{21}$.

(6) Apart from the effect of the various diets on the general condition of the child, the stool picture and the weight curve, the bowel condition, as judged by the sigmoidoscopic appearances, was not materially influenced. The various modifications of diet failed to bring about rapid cure of the disease.

\section{Conclusions}

1. Bacillary dysentery is a self-limited disease in which recovery depends upon the development of immunity on the part of the body. Until such immunity has developed, the disease will continue its course irrespective of the character of the diet.

2. The underlying principles of treatment should be to choose a diet that maintains nutritution until the body has developed sufficient resistance to overcome the infection. The value of the various diets in maintaining this point has already been considered.

3. The sigmoidoscope can be safely used in infancy. It affords rapid and accurate means of diagnosis of dysenteric conditions. The course of the disease can be closely followed and the onset of final cure definitely established.

\section{REFERENGES}

1. Manson-Bahr, P., Manson's Tropical Diseases, ninth edition, London $1929,394$.

2. Alexeiff, A., Zentralbe. f. Bakt., Jena, 1927, CIII, 354.

3. Martin, C. J., \& Williams, C. F., Roger's Rec. Adv. in Trop. Med., London, 1929, 218. 
4. Shawki, I., Coup. Rend., Congrés Internat. de Méd. Trop. et d' Hyg., Cairo, 1928, II, 929.

5. Thomson, J., \& Findlay, L., Clinical Study \& Treatment of Sick Children, fifth edition, Edinburgh, 1933, 225.

6. Feer, E., Lehrb. Kinderheilk., eleventh edition, Jena, 1934, 630.

7. Hassman, K., \& Herznann, K., Ztschr. f. Kinderh., Berlin, 1934, LVI, 609.

8. Zahorsky, J., Southern Med. J., Birmingham, Ala., 1928, XXI, 395.

9. Le Noir, P., and Deschiens, R., Arch. d. mal. de l'app. digestif., Paris, 1924, XXIV, 919.

10. Magath, T. B., \& Brown, P. W., Am. J. Trop. Med., Baltimore, 1930, X, 113.

11. Friedmann, Roger's Rec. Adv. Trop. Med., London, 1929, 218.

12. Biggam, A. G., \& Arafa, H. A., Trans. Roy. Soc. Trop. Med., Hyg., London, 1930-31, XXIV, 187.

13. O'Connor, F. W., Proc. Assam Branch, B.M.A., Jorhat, 1925, 29.

14. Albert, J., \& Quaison, J. O., J. Phillippine Islands Med. Assoc., Manila, 1927, VII, 246 .

15. Meyer, L. F., \& Nassau, E., Die Säulglingsernährung, Munich, 1930, 214.

16. Bessau, G., Deutsch. med. Wchnschr., Leipzig, 1925, LI, 723.

17. Rosenbaum, S., Monatschr. f. Kinderh., Leipzig, 1926, XXXIII, 441.

18. Fasold, H., ibid., 1934, LX, 169.

19. Baumann, T., \& Forsehener-Böke, H., Ztschr. f. Kinderh., Berlin, 1934, LVI, 514.

20. Czerny, A., \& Keller, A., Des Kinds Ernährung, Ernährungsstör U. Ernährungstherapie, second edition, Leipzig, 1928.

21. Iskander, F., J. Egypt. Med. Ass., Cairo, 1935, XVIII, 134. 